\title{
A METHODOLOGY FOR VIRTUAL ASSESSMENT OF PRODUCT ERGONOMICS
}

\author{
Giorgio Colombo \\ Department of Mechanics \\ Polytechnic of Milan, Italy \\ giorgio.colombo@polimi.it
}

Daniele Regazzoni \& Caterina Rizzi

Department of Engineering

University of Bergamo, Italy

daniele.regazzoni@unibg.it; caterina.rizzi@unibg.it

\begin{abstract}
This paper presents a method, which integrates digital human models (DHM) and virtual prototyping techniques to analyse ergonomic issues of devices to be used by workers. It is based on the comparison between the analysis of AS-IS and TO-BE scenarios with the aim of assessing design concepts, highlighting improvements or worsening and residual deficiencies to be faced. In particular, this paper refers to the case study of display units for groceries or supermarkets. Actually, workers who are in charge of filling the shelves perform highly repeated tasks, potentially dangerous for their health. The AS-IS and TO-BE analysis compares the actual practices with a new scenario in which workers are provided with lifting platforms to load the shelves. The method allows assessing several ergonomics parameters; in this study posture and fatigue are the most relevant. The results achieved with the simulations permitted to propose alternative solutions. Future works in this field concern the standardization of domain dependant actions virtual human are asked to perform.
\end{abstract}

\section{KEYWORDS}

Digital human models (DHM), ergonomics analysis, display unit, design validation, lifting aids, OWAS, NIOSH, posture, fatigue,

\section{INTRODUCTION}

Computer aided design and engineering tools are the pillars of product development process; however, designers have to take into account that whenever a person is supposed to interact with a device, a machine or a plant, he or she must be included in the simulation of the overall system. This means that the design process, in some specific steps, should be centred on human beings to ensure suitable products and production processes to the widest range of population. The adoption of proper development paradigms exploiting human simulation tools permits to consider ergonomics aspects since the early stages of the design process. By the way, ergonomics and digital human simulations are hardly integrated in the design process, in particular in SMEs, due to several potential reasons among which the "never used so far" syndrome, the inertia to change design paradigm and the difficulties in determining cost and benefits. This paper refers to this context and, in order to ease the introduction of virtual ergonomics in industry, it shows a method based on the use of techniques to design auxiliary equipment specifically conceived to load display unit. In particular, DHM tools have been used to evaluate three different solutions according to the specific needs of supermarket operators to guarantee good health conditions. The paper first introduces the context of the research and the problem we need to address. Later on the proposed method is exposed and a state of the art on tools for assessing ergonomics and about DHM is reported. The application of the paradigm to the case study of display units shows the way it works in details and provides data for the following discussion section. Some conclusions and reflections on further development complete the paper. 


\section{CONTEXT}

Musculoskeletal disorders (MSDs) are a major issue among several kind of workers in industry and services and constitute a leading cause in work disability and lost productivity (National Academy of Science, 2001). In the United States MSDs, such as sprains and strains, are the cause of more than a half of work related injury or illness (Department of Labour, 2003) and according to (Regimster, 2002) the annual costs for MSDs exceed those of cancer as contributors to occupancy related health care costs. In Europe $24 \%$ of workers from 25 UE countries suffers of back pain and 22\% reports muscular suffering (European Agency for Safety and Health at Work, 2007). These figures highlight a critical health condition among a considerable number of workers and, on the other side, they give a measure of the huge cost companies and national healthcare systems are asked to pay for. The most common work related diseases are due to repeated tasks and affect mainly the trunk causing back pain. The standard UNI EN 1005-4 (UNI-EN 2005; 2007) provides indications to prevent or mitigate such problems, but without a proper re-design of work environment it results to reduce operators' freedom and productivity and, thus, it is frequently neglected.

MSDs are affecting workers normally performing tough operations with a high frequency as, for instance, repeated lifting of heavy weights. In these cases the most diffused pathologies concerns: neck and shoulder, due to wrong posture; forearm and hand due to muscular overload; low back pain mainly due to wrong way of lifting heavy weights. Nevertheless, even if figures depict a dramatic situation, industry is under reacting to the problem, SMEs less than big enterprises. In this context the goal of this work is to exemplify how a nondisruptive method can be quite easily introduced in the design process to start managing ergonomics and, may be, also gathering a competitive profit.

\section{PROBLEM ANALYSIS}

As mentioned before in this paper we refer to supermarket and grocery workers; they are exposed to highly repeated operations that may create conditions leading to ailments or disease. In particular, display unit is a meaningful product because it allows testing different people dealing with it: workers in charge of filling up the shelves with new goods, technicians maintaining the display unit (e.g., refrigerated ones) and customers who need to see and grab exposed goods.

A preliminary research on the way operators of supermarkets really behave has been conducted (see Figure 1). Interviews and observations of personnel in charge of loading display units highlighted some occasional unacceptable practices, e.g., stepping onto the first shelf of the display unit to better reach the highest one (see Figure 1-c).
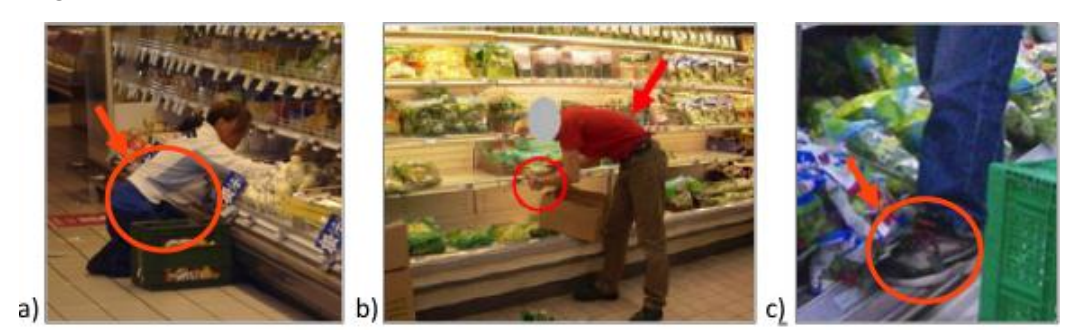

Figure $1(\mathrm{a}, \mathrm{b})$ postures assumed by operators, (c) operator stepping on the cabinet

This work provides a methodological approach to analyse ergonomic issues of operators using equipment specifically designed to load refrigerated display units. Together with the company EPTA that designs and produces this kind of cabinet, we decided to take as test case a refrigerated display. Actually, it is the most challenging device, not because of the cold environment, which does not affect the evaluation, but because this is the most frequently checked and re-filled and the only one that may have closing door which is a further disturbing factor for the loading tasks.

The proposed approach allows evaluating the way operators act today, i.e. without proper working conditions and rules of behaviour, and to assess improvements of proposed technical solutions to make better working conditions. In other words, the goal is to show how to provide technicians with right tools to design operator centred devices, reducing dramatically MSDs occurrence. 


\section{APPROACH AND TOOLS}

The method is intended to be integrated in the conceptual design process in order to face ergonomic issues before entering in the detailed design where the cost of a design review highly increases. According to standard design process and to company's practice shown in Figure 2, after the definition of a new product concept some test are performed to avoid major issues that could compromise the entire process. When manufacturing and thermodynamic checks are passed the first analysis to be done concern ergonomics, while normally this evaluation is done much later during design optimization. Actually, the trend of standards and regulations are suggesting ergonomics will be a key issue in a few years even if in western countries at the moment there are no specific constraints.

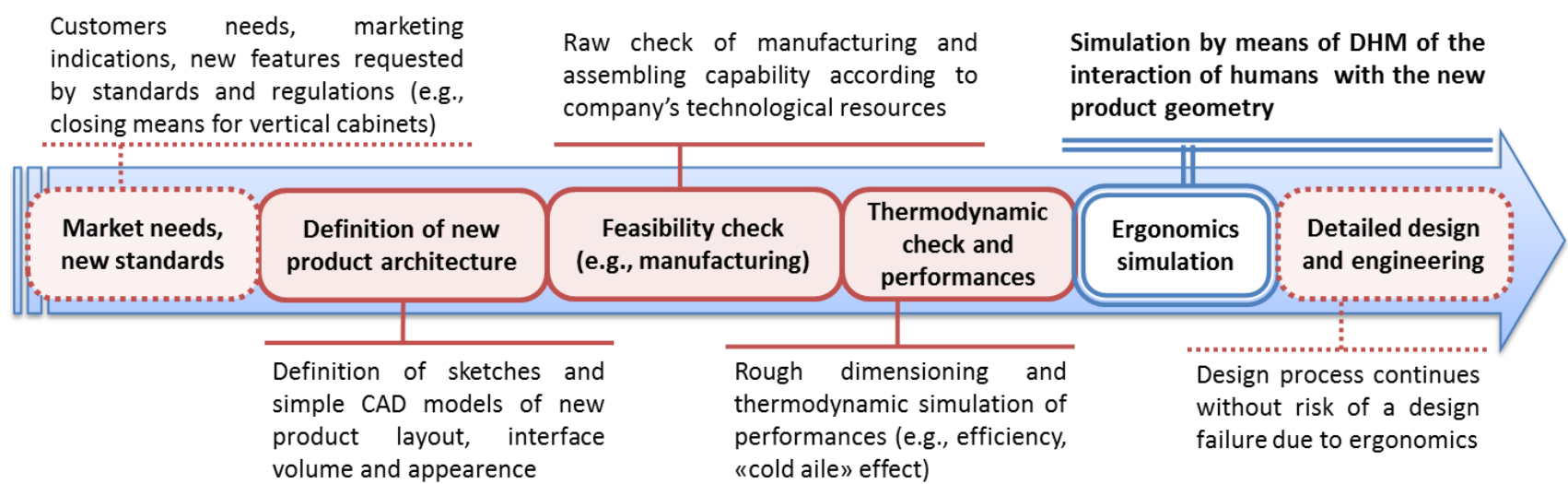

Figure 2 Conceptual design process including ergonomics simulation

The method we propose for ergonomics analysis is composed by three main steps (Figure 3) in which simulation campaigns are carried out. For each simulation we preliminary need to define the work environment in terms of devices and products the operator will deal with. For the case study we considered the refrigerated cabinet, its shelves and displayed packed goods. Moreover, we need also to define workers in terms of the task they accomplish and their posture and to select the parameters to be checked, e.g. visibility, reachability, and spine load. For the considered case study the working postures and the movements are related to pick and place operations on the cabinet; in fact, operators are exposed to repetitive tasks that can cause stress and pain. This should allow engineers to design machinery reducing as much as possible painful and tiring postures and movements and, thus, health risk.

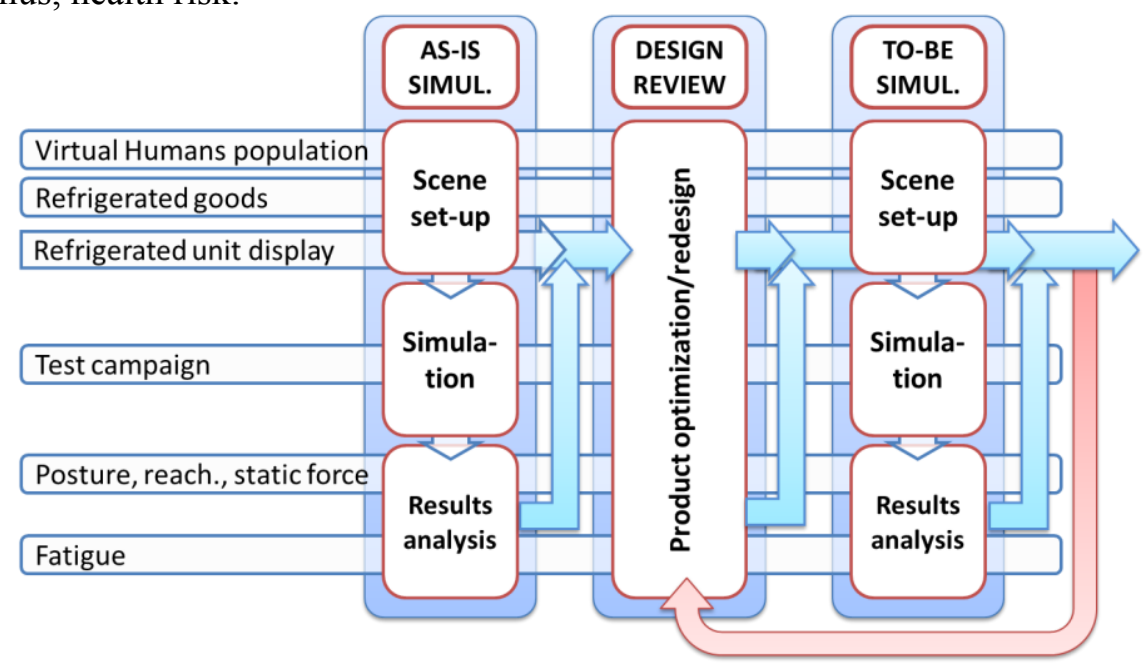

Figure 3 Method to evaluate design by means of As-Is and To-Be ergonomics simulations

Once environment, workers and parameters to measure are defined, three steps must be accomplished as reported in Figure 3:

1. Simulate As-Is configuration: analyse the actual design taking into account operators' working conditions. 
2. Design review: compare simulation data and, if necessary, propose and check further solutions for unsolved problems.

3. Simulate To-Be configurations: evaluate the impact of the changes made to the product or to the working environment to solve ergonomics issues.

The first step has the goal of defining the reference scenario, finding eventual risky operations and margins to improve performances. This activity is normally performed on an existing product but it can also be done on a brand new idea since for the simulation with DHM we just need a preliminary rough sketch of the product.

The design review activity has the goal of defining new tentative solutions that should overcome As-Is limits. The results gathered highlight one, or a few, preferred solutions and trigger for further innovations. Any change in the way operators work can be suggested here. For instance, in the case study the new design solutions consist in proposing three different platforms where the worker can step on and perform pick and place operations from a more convenient position.

The second campaign of simulations is aimed at evaluating the benefits gathered (or the risk reduction), and the improvement introduced by the preferred designs. Moreover, residual minor issues can be addressed by proposing further alternative or complementary solutions before going ahead with the design process. In the case study, platforms are solving issues only for the highest shelves and cannot address loading problems of the lowest, for which new solutions are found and tested.

As any design method this as well suffers from being iterative. To-Be solutions may not meet the requirements and steps 2 and 3 may cycle some times. By the way the time and the resources consumed by these activities are so small this does not affect significantly the whole length of the design process. Moreover, this method prevents mistakes that, discovered at the end of an entire product development process, would cost much more. To make the proposed paradigm a concrete working procedure we analysed the state of the art of two different domains: criteria to evaluate ergonomics of workers and Digital Human Modelling tools.

\subsection{ERGONOMICS CRITERIA AND INDEXES}

Analysing ergonomics is a complex matter that requires different methods to say whether a posture is good or not, or if an easy task would provide harm to workers when repeated several times eventually without a proper recovery time. In the followings the methods considered for this goal are briefly presented.

The main reference is the National Institute of Occupational Safety and Health (NIOSH) (Centre for Disease Control and Prevention, 2013), which has developed a method to evaluate risks that may occur during manually lifting and moving loads. In particular, the NIOSH lifting equation (DHHS 1994) takes into account the weight plus several other variables that contribute to the risk of injury in lifting tasks. For example, if the situation requires frequent lifts or lifting loads far away from the body, there is an increased risk of injury. Under these conditions, the weight limit would be reduced from a baseline weight or "load constant" (LC) to a recommended weight limit (RWL).

In case of multi task operations in which the worker performs several different movements eventually holding a load, the assessment is more complex and two other NIOSH indexes are needed: Composite Lift Index (CLI) and Sequential Lifting Index (SLI).

Once all parameters and values regarding the task to be performed and the (virtual) human anthropometric data are available, it is possible to perform different kinds of analysis to get a complete assessment of the task simulated. NIOSH indexes, as well as posture evaluation, lower back analysis, static force prevision and recovery times can be gathered, as follows:

- RWL: represents the weight limit to avoid musculoskeletal issues. It depends on biomechanical and physiological aspects.

- LI (Lift Index): it is the ratio among the weight of the real load and the RWL. It gives a measure of the effort the worker is asked to accomplish.

- Posture evaluation according to OWAS (Owako Working-posture Analysis System) method (Karhu et al., 1977). This method allows assessing the quality of postures evaluating back, forearms and legs position and external load. There are 4 Owas classes where 1 corresponds to the natural optimal condition and classes from 2 to 4 show an increasing hazard of operations and the need for changing the workstation.

By performing a Lower Back Analysis it is possible to perform an evaluation in each step of the movement to determine some other indexes, such as the compression load on lumbar vertebrae 4 and 5 (L4/L5). 
A correct timing in repetitive tasks is a key factor to balance productivity and stress of operators. By an appropriate simulation of the work an operator must perform it is possible to:

- Determine those operations, which hardly create fatigue conditions and, thus, do not require any control on recovery time.

- Highlight operation that are main responsible for fatigue.

- Calculate, when needed, recovery time for any working cycle.

For the case study we calculated almost all the indexes with the aim of assessing the As-Is scenario for any further comparison that will be made in the future. NIOSH indexes were assessed for the pick and place operation. Standard operation is composed by:

- Picking up the good from the ground (for the lowest shelf) or from a support at $50 \mathrm{~cm}$ from the ground;

- Placing the good on the maximum distance reachable on every shelf.

OWAS class were determined for the worst posture assumed, i.e., corresponding to the maximum reachability for each shelf for each virtual human size.

\subsection{DIGITAL HUMAN MODELLING TOOLS}

Digital Human Models are becoming more and more popular, especially in defence, aeronautics and automotive fields. Digital human modelling started in the 1960s and, at present, various frameworks of different complexity are commercially available, most of them originated from research activities (Duffy, 2003; Sundin and Ortengren, 2006; Magnenat-Thalmann and Thalmann, 2004).

From the analysis of literature, DHMs can be subdivided into four main categories (Colombo et al., 2011):

- Digital humans/actors for entertainment mainly considered to populate scenes for movies and videogames. Crowd simulators (Thalmann et al., 2009) belong to this group too and they can be used to simulate emergency situations (e.g., building construction) and for training purposes.

- Virtual manikins for clothing used to create virtual catwalks, catalogues, try-on show rooms and to design garments (Magnenat-Thalmann and Thalmann, 2004).

- Virtual humans for ergonomic analysis used to assess compatibility and usability of products, machinery or workplaces for the human user or operator. Jack (Badler, 1993; Siemens PLM, 2013) Ramsis (Van der Meulen and Seidl, 2007), Safework (DELMIA, 2013) and HumanCAD (NEXGEN, 2013) are some examples of commercial frameworks. They permit to create complex scenes, analyse postures, simulate tasks and optimize working environments. This type of virtual humans can be used by a wide range of companies, from more classical ones, such as automotive and aeronautics, to house appliance, medical devices and consumables. For example, in automotive the applications range from ergonomic design of car interior (Van der Meulen and Seidl, 2007; Colombo and Cugini, 2005) to comfort analysis and manufacturing processes (Berger et al., 2004; Mueller and Maier, 2009); while in aeronautics, they are used to design more efficiently the airplane interiors, such as the cockpit (Zhang et al., 2007; Nadadur and Parkinson, 2009; Green and Hudson, 2011; Dantas Alves Silva, 2007) but also to study loading and unloading systems of luggage in airports (Liem and Yang, 2004).

- Detailed biomechanical models (Dao et al., 2010; Bucca et al., 2009) considered for computing biomechanical system kinematics using forward and inverse kinematics algorithms. They are characterised by a complete biomechanical model and are more complex model than the previous ones. They are usually structured into three distinct components: the skeleton with deformable elements and joints, skin and muscle tissues, tendons and ligaments. Some examples are LifeMOD (Lifemodeler, 2013), MADYMO (Tass International, 2013), and Santos (Abdel-Malek, 2009).

We can also find researches that integrate DHM either with VR (Virtual Reality) systems (Colombo et al., 2010; Bordegoni et al., 2008) to improve the level of interaction and realism within the virtual environment or with Mocap (Motion Capture) equipment to drive the virtual human and facilitate the evaluation of comfort and prediction of injuries that could rise when executing a task.

To conclude, the potential application range of virtual humans is huge, and companies from different industrial contexts should be considering their use during the product development process. By the way, inertia to change design paradigm and a lack of operative method limit a broad diffusion of DHM tools. 
For this case study we decided to use the ergonomics oriented tool named Jack that is particularly suitable for the simulation we have to perform and provide a powerful post-processing module to determine the main parameters we want to measure. Moreover it is quite simple to be used and does not require a long training to be productive.

\section{APPLICATION AND RESULTS}

This paragraph shows the way simulations are set up and run according to the presented a step-by-step method. Each run of the simulation consists of three parts, as shown in Table 1: the first one is dedicated to the set-up of the virtual environment in which the simulation takes place, in the second the test campaign is defined and simulation are run and, at last, the third is dedicated to the analysis of results according to ergonomic standards and eventual issues still to be solved are identified.

Table 1 Parameters and values for a simulation

\begin{tabular}{|c|c|c|}
\hline & Parameters & Values \\
\hline \multirow{3}{*}{$\begin{array}{l}\text { 1. Scene } \\
\text { set-up }\end{array}$} & Virtual human population & female $5^{\text {th }}, 50^{\text {th }} \mathrm{PCT}$; male $50^{\text {th }}, 95^{\text {th }} \mathrm{PCT}$ \\
\hline & Refrigerated goods & cartoon box, $200 \times 140 \times 70 \mathrm{~mm}, 1 \mathrm{~kg}, 3 \mathrm{~kg}$ \\
\hline & Refrigerated unit display & vertical, open, 5 shelves, $2110 \mathrm{~mm}$ height \\
\hline $\begin{array}{c}\text { 2. Test } \\
\text { campaign }\end{array}$ & Simulation & w/out platform, shelf \#1, shelf \#5 \\
\hline \multirow{2}{*}{$\begin{array}{l}\text { 3. Result } \\
\text { analysis }\end{array}$} & Posture, reachability & max reachability, OWAS class \\
\hline & Fatigue, force & $\begin{array}{l}\text { lower back analysis, static force, fatigue } \\
\text { and recovery time }\end{array}$ \\
\hline
\end{tabular}

For each analysis the virtual human chosen to represent operators are females of 5th and 50th percentile and males of 50th and 95th percentile according to ANSUR (NSRDEC, 2013) anthropometric database as reported in Table 2.

Table 2 Main anthropometric data of selected virtual humans

\begin{tabular}{|lcccc|}
\hline $\begin{array}{c}\text { Gender } \\
\text { PCT }\end{array}$ & $\begin{array}{c}\text { Male } \\
95^{\text {th }}\end{array}$ & $\begin{array}{c}\text { Male } \\
\mathbf{5 0}^{\text {th }}\end{array}$ & $\begin{array}{c}\text { Female } \\
\mathbf{5 0}^{\text {th }}\end{array}$ & $\begin{array}{c}\text { Female } \\
5^{\text {th }}\end{array}$ \\
\hline $\begin{array}{l}\text { Height } \\
(\mathrm{cm})\end{array}$ & 187 & 175 & 163 & 153 \\
\hline $\begin{array}{l}\text { Weight } \\
(\mathrm{kg})\end{array}$ & 98 & 78 & 61 & 50 \\
\hline
\end{tabular}

The vertical refrigerated display unit shown in Figure 4 has been taken as an example since it is considered a good representative of vertical unit family. At first, the current version of the refrigerated display unit was simulated; then, lifting platforms were introduced and new simulation run. After that an iteration of steps 2 and 3 was performed to overcome issues not addressed with platforms.
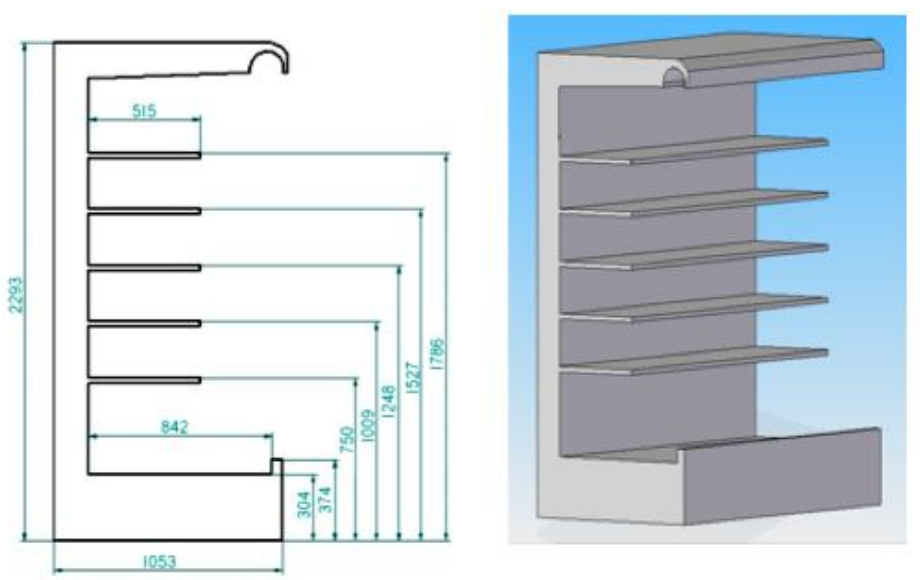

Figure 4 Refrigerated vertical display unit model 
Concerning the setup of the virtual scene, two libraries have been developed. The first includes simplified 3D models of the refrigerated units where parts specifically involved in the ergonomics analysis have been parameterized to be easily modifiable (e.g., shelves sizes, positions and number). The latter one comprehends a set of 3D parametric product models adaptable to represent a wide range of goods. Product weight goes from $1 \mathrm{~kg}$ to $3 \mathrm{~kg}$ since lighter goods are not critical and heavier normally are not handled manually.

\subsection{AS-IS ANALYSIS}

For each given display unit, each virtual human and each product to handle, simulations are needed to evaluate ergonomics depending on which shelf of the display unit is considered. Actually, the intermediate shelves do not require the operator to adopt uncomfortable postures, while loading the first shelf (lowest) and the last shelf (highest) is more challenging in terms or reachability, visibility and postures assumed. To load the first shelf operators might have to stay down on their knees and to reach the last shelf they often step up on the cabinet neglecting any basic safety and hygienic recommendation. For the first shelf virtual operators have been put in different configurations (i.e., sitting, kneeling in front or aside of the display unit) to find the better posture. For the last shelf we have also simulated operators stepping up the cabinet, not to take this as a viable configuration in the future, but to perform a more realistic comparison with new technical solutions.

For each configuration, ergonomics parameters and indexes have been gathered according to the methods described in the fourth paragraph. Figure 5 shows, for instance, a woman of 5 th percentile a man of 95 th percentile positioning a $1 \mathrm{~kg}$ load to their maximum extent on the lowest shelf. Table 3 summarizes the results obtained for the four virtual humans performing the same task.

a)
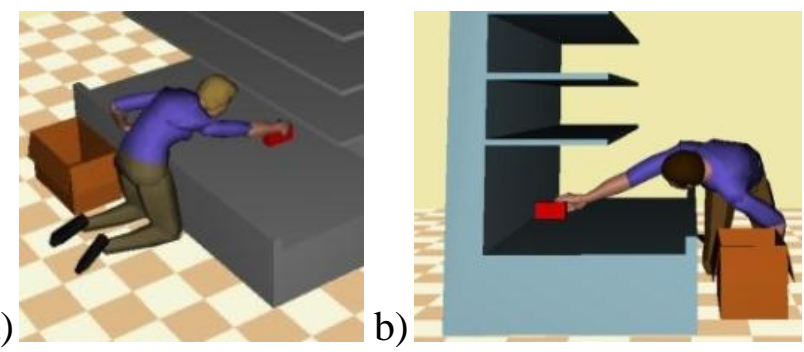

Figure 3 Posture assumed by 5th percentile woman and 95th percentile man to load lowest shelf

Table 3 AS-IS analysis results for lowest shelf

\begin{tabular}{|c|c|c|c|c|c|c|c|}
\hline \multicolumn{4}{|c|}{$\begin{array}{l}\text { AS-IS } \\
\text { LOWEST SHELF }\end{array}$} & $\begin{array}{c}\text { Female } \\
\mathbf{5} \%\end{array}$ & $\begin{array}{c}\text { Female } \\
50 \%\end{array}$ & $\begin{array}{c}\text { Male } \\
50 \%\end{array}$ & $\begin{array}{c}\text { Male } \\
95 \%\end{array}$ \\
\hline \multicolumn{3}{|c|}{ REACHABILITY } & $\%$ reached & 80 & 85 & 100 & 100 \\
\hline \multicolumn{3}{|c|}{ POSTURE } & Owas class & 2 & 2 & 4 & 4 \\
\hline \multirow{6}{*}{\multicolumn{2}{|c|}{$\begin{array}{l}\text { Load } \\
1 \mathrm{Kg}\end{array}$}} & \multirow{4}{*}{$\begin{array}{c}\text { Lower } \\
\text { Back } \\
\text { analysis }\end{array}$} & L4L5 (Nm) & 25 & 80 & 120 & 125 \\
\hline & & & $\begin{array}{l}\text { Spinal } \\
\text { Forces(N) }\end{array}$ & 800 & 1500 & 2400 & 2600 \\
\hline & & & $\begin{array}{l}\text { Muscle } \\
\text { tension (N) }\end{array}$ & 200 & 520 & 1100 & 1100 \\
\hline & & & Static force & 390 & 390 & 450 & 430 \\
\hline & & \multirow{2}{*}{$\begin{array}{l}\text { Fatigue - } \\
\text { recovery }\end{array}$} & Cycles & 30 & 30 & 26 & 25 \\
\hline & & & $\begin{array}{l}\text { Recovery } \\
\text { Time (s) }\end{array}$ & 0,45 & 0,57 & 10,16 & 11,95 \\
\hline \multirow{9}{*}{$\begin{array}{l}\text { G } \\
\text { U } \\
\text { E }\end{array}$} & \multirow{6}{*}{$\begin{array}{l}\text { Load } \\
3 \mathrm{Kg}\end{array}$} & \multirow{4}{*}{$\begin{array}{c}\text { Lower } \\
\text { Back } \\
\text { analysis }\end{array}$} & L4L5 (Nm) & 75 & 85 & 125 & 130 \\
\hline & & & $\begin{array}{l}\text { Spinal } \\
\text { Forces (N) }\end{array}$ & 1500 & 1600 & 2600 & 2900 \\
\hline & & & $\begin{array}{l}\text { Muscle } \\
\text { tension (N) }\end{array}$ & 520 & 600 & 1200 & 1250 \\
\hline & & & Static force & 410 & 410 & 465 & 470 \\
\hline & & \multirow{2}{*}{$\begin{array}{l}\text { Fatigue - } \\
\text { recovery }\end{array}$} & Cycles & 28 & 28 & 18 & 13 \\
\hline & & & $\begin{array}{l}\text { Recovery } \\
\text { Time (s) }\end{array}$ & 4,48 & 4,536 & 30,28 & 37,89 \\
\hline & \multirow{3}{*}{\multicolumn{2}{|c|}{ NIOSH }} & $\mathrm{RWL}^{(1)}$ & 3,88 & 3,65 & 3,37 & 3,65 \\
\hline & & & $\mathrm{LI}^{(2)}$ & 0,39 & 0,41 & 0,45 & 0,41 \\
\hline & & & $\mathrm{CLI}^{(3)}$ & 1,393 & 1,478 & 1,605 & 1,478 \\
\hline
\end{tabular}

(1) Reccommended Weight Limit; (2) Lifting Index; (3) Composite Lifting Index 
We can observe that females cannot reach the back of the shelf with a posture that is barely acceptable (OWAS class 2), while males can reach $100 \%$ of the shelf but assuming a posture (OWAS class 4 ) that is risky and requires urgent correction. On the contrary, the resulting values obtained for lower back analysis, static strength and fatigue are not critical. The shift of the load from $1 \mathrm{~kg}$ to $3 \mathrm{~kg}$ does not produce any change in the muscular load distribution while forces increase. Work cycles and recovery times are particularly positive for females handling the load of $1 \mathrm{~kg}$, while for the highest male with the heaviest load they are disadvantageous.

\subsection{TO-BE ANALYSIS}

After completing the simulations reproducing the loading task as they are performed nowadays by real supermarket operators, three different potential lifting platforms have been tested (see Figure 6). Platforms are intended to lift the operator and a certain quantity of goods to be placed on the highest shelf of the display unit.

A)

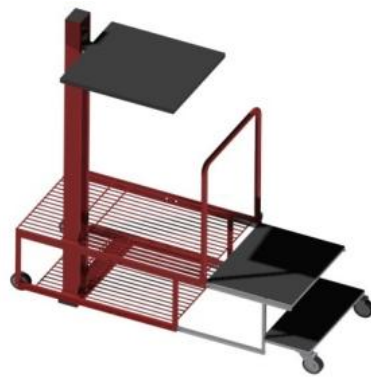

B)

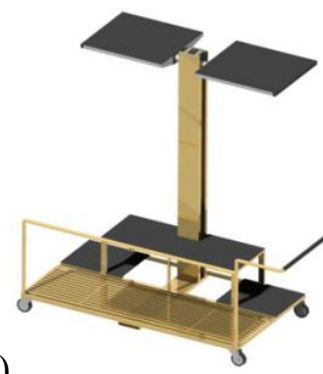

C)

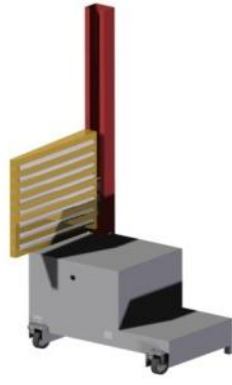

Figure 6 Three designs of lifting platform

The analyses have been carried out according to the parameters of the AS-IS analysis so that results are easily comparable. Figure 7 shows, for instance, the male 50th percentile on the three platforms reaching the back of the shelf (left and centre) and in the starting position (right).

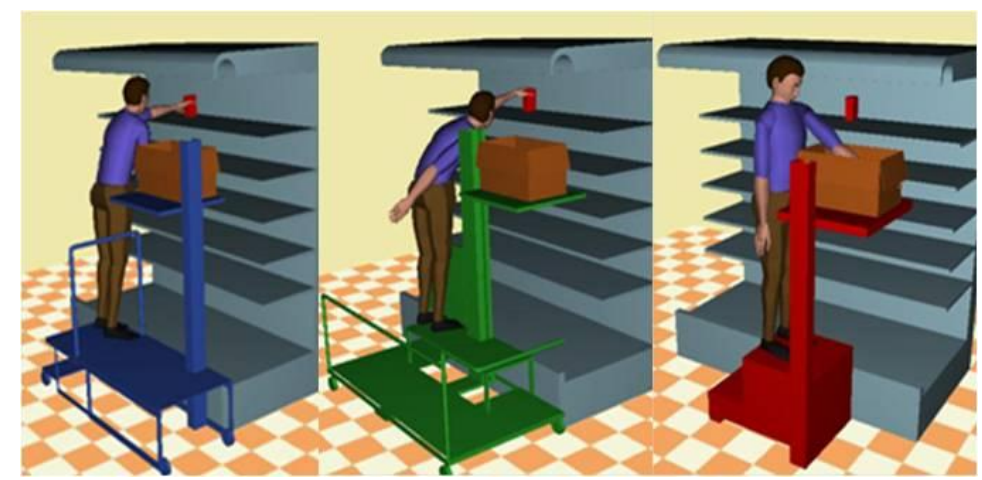

Figure 7 50th percentile man loading shelf standing respectively on the lifting platforms A, B and C

Results have been quantified and, then, compared with those of the previous campaign (see Table 4).

The main result is that the platform increases females' ability to get closer the back of the highest shelf, but their OWAS class worsens. Actually, platforms set all the virtual humans back from the display unit determining, for some of them, the worsening of some evaluation parameters. By the way the comparison is done with the As-Is in which virtual humans were standing on the cabinet, while using the platform is a perfectly viable and safe solution. 
Table 4 To-Be analysis results for highest shelf and platform c, compared to As-Is results

\begin{tabular}{|c|c|c|c|c|c|c|c|c|c|c|c|}
\hline \multirow{2}{*}{\multicolumn{3}{|c|}{$\begin{array}{l}\text { TO-BE } 1 \\
\text { HIGHEST SHELF }\end{array}$}} & & \multicolumn{2}{|c|}{ Female 5\% } & \multicolumn{2}{|c|}{ Female $\mathbf{5 0} \%$} & \multicolumn{2}{|c|}{ Male $\mathbf{5 0} \%$} & \multicolumn{2}{|c|}{ Male $95 \%$} \\
\hline & & & & \multirow{2}{*}{\begin{tabular}{|c|} 
As-Is \\
40
\end{tabular}} & \multirow{2}{*}{$\frac{C \text { platf. }}{60}$} & \multirow{2}{*}{\begin{tabular}{|c|} 
As-Is \\
50 \\
\end{tabular}} & \multirow{2}{*}{\begin{tabular}{|c|} 
C platf. \\
85 \\
\end{tabular}} & \multirow{2}{*}{\begin{tabular}{|l|} 
As-Is \\
100
\end{tabular}} & \multirow{2}{*}{$\begin{array}{c}\text { C platf. } \\
100\end{array}$} & \multirow{2}{*}{\begin{tabular}{|l|} 
As-Is \\
100
\end{tabular}} & \multirow{2}{*}{$\begin{array}{c}\text { C platf. } \\
100\end{array}$} \\
\hline & CHAB & ILITY & $\%$ reached & & & & & & & & \\
\hline \multicolumn{3}{|c|}{ POSTURE } & Owas class & 1 & 3 & 1 & 3 & 3 & 2 & 2 & 2 \\
\hline \multirow{6}{*}{\multicolumn{2}{|c|}{$\begin{array}{l}\text { Loa } \\
1 \mathrm{~K}\end{array}$}} & \multirow{4}{*}{$\begin{array}{c}\text { Lower } \\
\text { Back } \\
\text { analysis }\end{array}$} & L4L5 (Nm) & 30 & 35 & 20 & 35 & 55 & 90 & 95 & 125 \\
\hline & & & \begin{tabular}{|l|} 
Spinal \\
Forces(N)
\end{tabular} & 800 & 900 & 500 & 1100 & 1200 & 2250 & 2050 & 3100 \\
\hline & & & \begin{tabular}{|l|} 
Muscle \\
tension (N)
\end{tabular} & 250 & 240 & 100 & 260 & 400 & 740 & 750 & 1100 \\
\hline & & & Static force & 150 & 150 & 150 & 150 & 275 & 420 & 390 & 500 \\
\hline & & \multirow[b]{2}{*}{$\begin{array}{l}\text { Fatigue - } \\
\text { recovery }\end{array}$} & Cycles & 25 & 28 & 27 & 26 & 29 & 28 & 8 & 25 \\
\hline & & & \begin{tabular}{|l|} 
Recovery \\
Time (s)
\end{tabular} & 8,19 & 4,7 & 4,03 & 8,24 & 0,12 & 4,84 & 2,17 & 11,77 \\
\hline \multirow{9}{*}{ I } & \multirow{6}{*}{$\begin{array}{l}\text { Load } \\
3 \mathrm{Kg}\end{array}$} & \multirow{4}{*}{$\begin{array}{c}\text { Lower } \\
\text { Back } \\
\text { analysis }\end{array}$} & L4L5 (Nm) & 45 & 40 & 25 & 40 & 70 & 105 & 110 & 150 \\
\hline & & & \begin{tabular}{|l|} 
Spinal \\
Forces (N)
\end{tabular} & 1000 & 1100 & 700 & 1400 & 1800 & 2700 & 2200 & 3250 \\
\hline & & & \begin{tabular}{|l|} 
Muscle \\
tension (N)
\end{tabular} & 270 & 260 & 240 & 400 & 500 & 800 & 770 & 1250 \\
\hline & & & \begin{tabular}{|l|} 
Static force \\
\end{tabular} & 150 & 150 & 420 & 150 & 280 & 450 & 390 & 500 \\
\hline & & \multirow{2}{*}{$\begin{array}{l}\text { Fatigue - } \\
\text { recovery }\end{array}$} & Cycles & 25 & 27 & 27 & 26 & 29 & 28 & 27 & 24 \\
\hline & & & \begin{tabular}{|l} 
Recovery \\
Time (s) \\
\end{tabular} & 10,3 & 7,74 & 5,07 & 10,4 & 1,23 & 5,6 & 2,75 & 13,24 \\
\hline & \multirow{3}{*}{\multicolumn{2}{|c|}{$\mathrm{NIOSH}$}} & $\mathrm{RWL}^{(1)}$ & 3,88 & 10,09 & 3,65 & 9,4 & 3,37 & 9 & 3,65 & 8,25 \\
\hline & & & $\mathrm{LI}^{(2)}$ & 0,39 & 0,15 & 0,41 & 0,19 & 0,45 & 0,17 & 0,41 & 0,18 \\
\hline & & & $\mathrm{CLI}^{(3)}$ & 1,39 & 0,54 & 1,48 & 0,57 & 1,6 & 0,6 & 1,47 & 0,65 \\
\hline
\end{tabular}

(1) Reccommended Weight Limit; (2) Lifting Index; (3) Composite Lifting Index

\subsection{ALTERNATIVE SOLUTIONS}

Even if the new solutions improve reaching the product and avoid some risky postures, some problems still remain. For example, in some case the presence of a shelf in the auxiliary equipment to support products box, hinders/limits operators' movements. Therefore, new design solutions have been proposed and tested by means of an iteration of the procedure. The solution consists in creating a platform, namely platform $\mathrm{D}$, that is able to rise and then to move towards the display unit getting the worker closer to the shelves (Figure 8). Table 5 highlights the results obtained for the highest shelf with virtual humans on platform D.
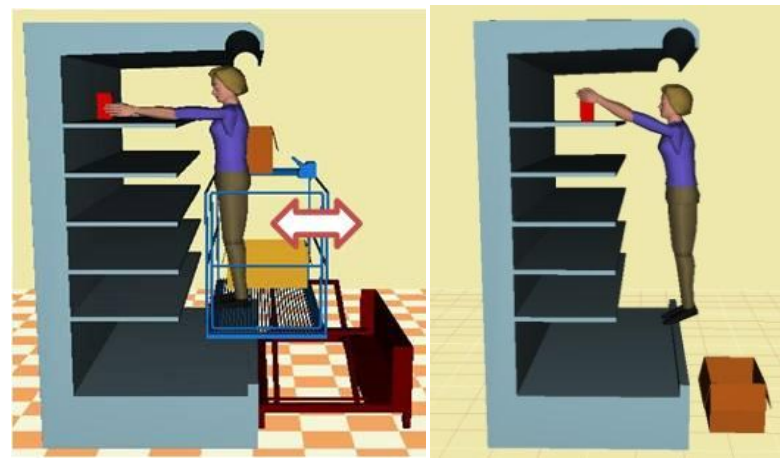

Figure 8 Comparison between platform d configuration and without platform for the highest shelf 
Table 5 Platform D analysis results for highest shelf compared to As-Is results

\begin{tabular}{|c|c|c|c|c|c|c|c|c|c|c|c|}
\hline \multirow{2}{*}{\multicolumn{3}{|c|}{$\begin{array}{l}\text { TO-BE } 2 \\
\text { HIGHEST SHELF } \\
\end{array}$}} & & \multicolumn{2}{|c|}{ Female 5\% } & \multicolumn{2}{|c|}{ Female $50 \%$} & \multicolumn{2}{|c|}{ Male $50 \%$} & \multicolumn{2}{|c|}{ Male $95 \%$} \\
\hline & & & & AS-IS & D platf. & AS-IS & D platf & AS-IS & D platf. & AS-IS & D platf. \\
\hline \multicolumn{3}{|c|}{ REACHABILITY } & $\%$ reached & 40 & 100 & 50 & 100 & 100 & 100 & 100 & 100 \\
\hline \multicolumn{3}{|c|}{ POSTURE } & Owas class & 1 & 2 & 1 & 2 & 3 & 1 & 2 & 2 \\
\hline \multirow{6}{*}{\multicolumn{2}{|c|}{$\begin{array}{l}\text { Lo } \\
11\end{array}$}} & \multirow{4}{*}{\begin{tabular}{|c} 
Lower \\
Back \\
analysis
\end{tabular}} & L4L5 (Nm) & 30 & 15 & 20 & 20 & 55 & 25 & 95 & 90 \\
\hline & & & \begin{tabular}{|l} 
Spinal \\
Forces(N)
\end{tabular} & 800 & 400 & 500 & 600 & 1200 & 900 & 2050 & 1900 \\
\hline & & & \begin{tabular}{|l|} 
Muscle \\
tension (N) \\
\end{tabular} & 250 & 50 & 100 & 130 & 400 & 210 & 750 & 700 \\
\hline & & & Static force & 150 & 150 & 150 & 150 & 275 & 220 & 390 & 340 \\
\hline & & \multirow{2}{*}{$\begin{array}{l}\text { Fatigue - } \\
\text { recovery }\end{array}$} & Cycles & 25 & 29 & 27 & 29 & 29 & 29 & 28 & 29 \\
\hline & & & \begin{tabular}{|l} 
Recovery \\
Time (s) \\
\end{tabular} & 8,19 & 0,36 & 4,03 & 1,44 & 0,12 & 0,27 & 2,17 & 1,77 \\
\hline \multirow{9}{*}{\begin{tabular}{|c}
$\mathrm{I}$ \\
$\mathrm{G}$ \\
$\mathrm{U}$ \\
$\mathrm{E}$
\end{tabular}} & \multirow{6}{*}{$\begin{array}{l}\text { Load } \\
3 \mathrm{Kg}\end{array}$} & \multirow{4}{*}{$\begin{array}{l}\text { Lower } \\
\text { Back } \\
\text { analysis }\end{array}$} & L4L5 (Nm) & 45 & 25 & 25 & 30 & 70 & 40 & 110 & 105 \\
\hline & & & \begin{tabular}{|l|} 
Spinal \\
Forces (N) \\
\end{tabular} & 1000 & 820 & 700 & 900 & 1800 & 1100 & 2200 & 2250 \\
\hline & & & \begin{tabular}{|l} 
Muscle \\
tension (N) \\
\end{tabular} & 270 & 200 & 240 & 220 & 500 & 250 & 770 & 550 \\
\hline & & & Static force & 150 & 150 & 420 & 155 & 280 & 225 & 390 & 340 \\
\hline & & \multirow{2}{*}{$\begin{array}{l}\text { Fatigue - } \\
\text { recovery }\end{array}$} & Cycles & 25 & 27 & 27 & 26 & 29 & 29 & 27 & 29 \\
\hline & & & \begin{tabular}{|l} 
Recovery \\
Time (s)
\end{tabular} & 10,3 & 6,64 & 5,07 & 9,78 & 1,23 & 2,04 & 2,75 & 3,07 \\
\hline & \multirow{3}{*}{\multicolumn{2}{|c|}{$\mathrm{NIOSH}$}} & $\mathrm{RWL}^{(1)}$ & 3,88 & 10,2 & 3,65 & 13,1 & 3,37 & 5,23 & 3,65 & 7,63 \\
\hline & & & $\mathrm{LI}^{(2)}$ & 0,39 & 0,15 & 0,41 & 0,11 & 0,45 & 0,17 & 0,41 & 0,2 \\
\hline & & & $\mathrm{CLI}^{(3)}$ & 1,39 & 0,54 & 1,48 & 0,42 & 1,6 & 0,61 & 1,47 & 0,72 \\
\hline
\end{tabular}

(1) Reccommended Weight Limit; (2) Lifting Index; (3) Composite Lifting Index

Concerning the lowest shelf some ideas were found to overcome postural issues and inefficiencies for short subjects. For instance, one consists in letting the bottom shelf move towards the operator, as shown in solution Figure 9, so that s/he can fill place goods from the side of the shelf.
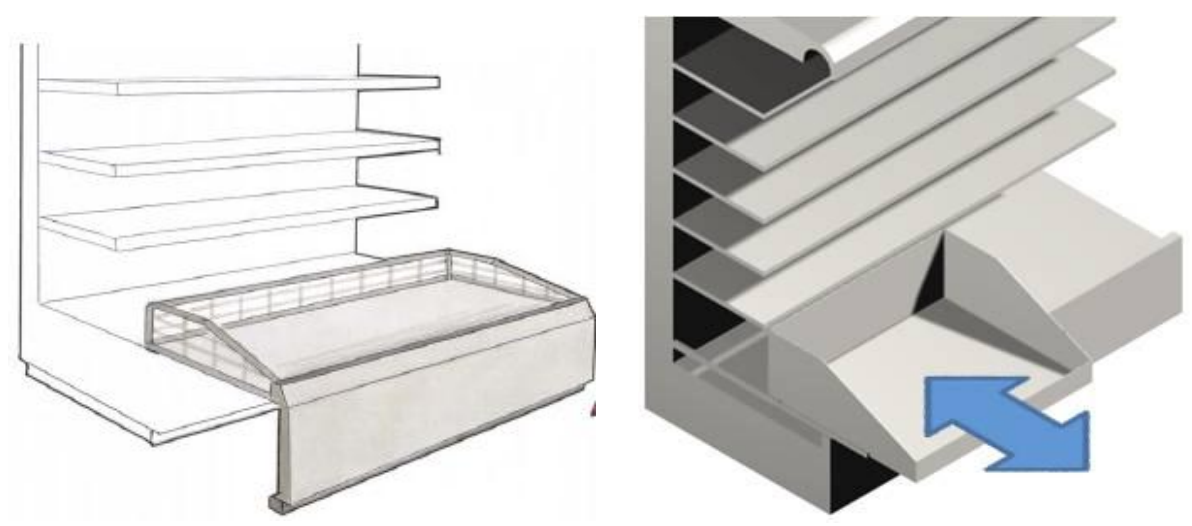

This kind of solves brilliantly the problem but is not feasible with existing display unit for safety reasons and, thus, it will be simulated with next generation of cabinets.

\section{DISCUSSION}

The application to the case study of the presented paradigm has highlighted some relevant points for discussion.

First of all we can see that in many configurations operators are not able to reach the back of the shelves. This means that in real life most probably workers will find a way to do it anyway adopting risky practices, such as stepping into the first shelf or climbing on other items not intended for that use.

Another aspect that comes into sight when analysing the outcomes of the simulation is that the OWAS class, for almost all tests, shows that the tasks, as they are performed at the moment, are extremely risky for workers' health, and, as a consequence, for companies employing them. For instance for the lowest shelf females cannot 
reach the back and assume a posture that is barely acceptable (OWAS class 2), while males can reach 100\% of the shelf but assuming a posture (OWAS class 4) that may cause disease and requires quick change.

For what concerns NIOSH indexes they are all below the recommended limits, mainly because the weight workers have to lift is much lower than the normal load considered. We decided to use NIOSH anyway to create a more complete set of referring data for any further change in the operation conditions. A complete analysis allows us also to create a reference set of postures and movement that will be used in the future for any other simulation on this cabinet or for other similar models.

Most of the problems on posture and reachability involve indirectly also display unit producers, as our research partner EPTA; therefore, some tentative solutions were designed to improve the situation. However, the intrinsic complexity of human body, of its degree of mobility and of the way it distributes loads make almost impossible to guess without proper tools whether a change in the man-machine interaction will lead to a benefit or a harm. For instance, the design of lifting platforms were performed by engineers without any indication from the As-Is simulation and the results is that to increase performances in terms of reachability, the platforms in the majority of occurrences worsen OWAS class. Actually, platforms set all the virtual humans back from the display unit determining, in particular for women, a worse posture (Table 4).

This constitutes practical evidence that DHM tools are so important that we can state that any engineer dealing with man-machine interaction should be able to simulate the working condition adopting a simulation tool based on virtual humans. The company collaborating in this research is highly interested in this kind of topics because the design of cabinets is mature and ergonomics aspects may introduce relevant innovations. They have evaluated positively the outcomes of this study, both at the level of the specific case study and at the level of the working paradigm adopted. On one side they are interested to the suggestion given to designer that never took into account ergonomics in this way; on the other they are willing to apply the same paradigm to some other products, such as power central units for maintenance operations. The creation of a systematic approach to make virtual ergonomics a part of the product development process will certainly bring dramatic benefits for the company.

\section{CONCLUSIONS}

Virtual human tools are not yet widely used among industry, even if poor ergonomics lead to a huge cost in term of missed production and work disability. The tools available on the market nowadays have reached good efficiency in terms of training time and experience needed to perform a complex simulation. According to authors' experience a few full time working days are enough for an average technician to be trained and perform autonomously some tests.

The limited diffusion of virtual humans tools out of the typical industrial areas in which they were born is mainly due to the lack of a structured approach. The synergic use of virtual humans and CAD techniques allows defining parametric databases of devices and handled products to be used in the virtual scene where the tasks are simulated. Dealing with an organized procedure, designer can concentrate on the development of TOBE solutions improving ergonomics as well as any other critical aspect of a system. Forecasting the way a person behaves in relation to a machine is not trivial; expecting to deal with such a complex problem without proper tools may bring to unexpected results. A systematic and organized use of the developed methodology allows designer taking into consideration the multiplicity of issues related to man-machine interface and to make human centred design a normal practice. The application to the refrigerated display unit highlights the benefits virtual humans can provide to the design of ergonomics-based devices to be used by operators. In order to perform even more accurate simulations workers' real postures and movements should be retrieved in their own workplace, also using a portable motion capture system.

\section{ACKNOWLEDGMENTS}

The author would like to thank in particular Dario Cimini and Alfredo Rottoli for their contributions to this work. Special thanks also to Giorgio De Ponti for his precious support.

\section{REFERENCES}

Abdel-Malek, K et al. (2009) 'A physics-based digital human model', International Journal of Vehicle Design, Vol. 51 No. 3/4, pp. 324-340. 
Badler, N., Phillips, C.B. and Webber, B.L. (1993) Simulating Humans: computer graphics animation and control, Oxford University Press, Oxford.

Berger, U., Lepratti. R. and Otte, H. (2004), 'Application of digital human modelling concepts for automotive production' in Proceeding of the TMCE 2004, 13-17 April, 2004, Lausanne, Switzerland.

Bordegoni, M., Caruso, G. and Ferrise, F. (2008), 'Mixed-Reality Environment based on Haptic Control System for a tractor cabin design review' in Proceeding of the CIRP Design Conference 2008, Enschede, The Netherlands.

Bucca, G, Buzzolato, A, Bruni, S, and Molteni, F. (2009) 'A Mechatronic Device for the Rehabilitation of Ankle Motor Function', Journal of Biomechanical Engineering, Vol. 131, No. 12 [online]. http://dx.doi.org/10.1115/1.4000083. (Accessed November 2012)

Center for Disease Control and Prevention, NIOSH. Ergonomic and musculoskeletal disorders. http://www.cdc.gov/niosh/topics/ergonomics/. [Accessed November 2012]

Colombo, G and Cugini. U. (2005) 'Virtual Humans and Prototypes to Evaluate Ergonomics and Safety', Journal of Engineering Design, Vol. 16 No. 2, pp. 195-203.

Colombo G, De Angelis F and Formentini L. (2010) 'Integration of virtual reality and haptics to carry out ergonomic tests on virtual control boards', International Journal of Product Development, Vol. 11 No. 1/2, pp. 47-61.

Colombo, G., Facoetti, G., Movigliatti, D. and Rizzi, C. (2011) 'A Virtual Human for lower limb prosthesis set-up', Proceedings of the ASME 2011 World Conference on Innovative Virtual Reality, WINVR2011, June 27-29, 2011, Milan, Italy.

Dantas Alves Silva, F.R., Rodrigues Miranda, M. and Reda, F. (2007), 'The Impact of the Digital Human Modeling on the Aircraft Interior Projects' in Proceeding of the Digital Human Modeling Conference, Seattle, WA, USA.

Dao, T.T., Pouletaut, F., Marin, P., Aufaure, P., Charleux, F., Ho Ba Tho. M.C. (2010), 'Simulation of the Gait of a Patient Specific Model of Post Polio Residual Paralysis (PPRP): effect of the orthosis' in Proceedings of the 3rd International Conference on the Development of BME, Vietnam.

DELMIA, Dassault Systèmes, Human Modelling Technology, Obtained through the Internet: http://www.3ds.com/products-services/delmia/solutions/human-modeling/ [Accessed July 2013].

Department of Labor, Bureau of Labor. Statistics, Safety and Health Program. (2003) Survey of occupational injuries and illnesses. Nonfatal (OSHA recordable) injuries and illnesses. Case and demographic characteristics. Washington, DC. http://www.bls.gov/iif/oshcdnew.htm, [Accessed July 2013].

Duffy VG (Ed.), (2007) Digital human modelling, HCI 2007, vol. LNCS 4561, Springer, Berlin.

European Agency for Safety and Health at Work. (2007) Work-related musculoskeletal disorders: Back to work report. Luxembourg. http://osha.europa.eu/en/publications/reports/7807300, [Accessed July 2013].

Green, R.F. and Hudson, J.A. (2011) 'A Method for Positioning Digital Human Models in Airplane Passenger Seats', in Duffy VG (Ed.), Advances in Applied Digital Human Modeling, CRC Press.

Karhu, O, Kansi, P and Kuorinka, I. (1977) 'Correcting working postures in industry: A practical method for analysis', Applied Ergonomics, Vol. 8 No. 4, pp.199-201.

Liem, A. and Yang, H. (2004), 'Digital Human Models in Work System Design and Simulation' in Proceeding of the Digital Human Modeling for Design and Engineering Symposium, Rochester, MI, USA.

Lifemodeler, (2013) Bringing simulation to life, Products and Services. Obtained through the Internet: http://www.lifemodeler.com/products/ [Accessed July 2013]

Magnenat-Thalmann, N, Thalmann, D (Eds.), (2004) Handbook of Virtual Humans. John Wiley \& Sons, Chichester, UK.

Mueller, A. and Maier, T. (2009), 'Vehicle Layout Conception Considering Vision Requirements - A Comparative Study within Manual Assembly of Automobiles' in Proceeding of the Digital Human Modeling for Design and Engineering Conference and Exhibition, Gothenburg, Sweden.

Nadadur, G, Parkinson, M. (2009), 'Using Designing for Human Variability to optimize Aircraft eat Layout' in Proceeding Digital Human Modeling for Design and Engineering Conference and Exhibition, Gothenburg, Sweden.

National Academy of Sciences. (2001) Musculoskeletal disorders and the workplace: Low back and upper extremities. National Academy Press, Washington, DC. 
NEXGEN Ergonomics (2013) HumanCAD Product Series Overview. Obtained through the Internet: http://www.nexgenergo.com/ergonomics/humancad_prods.html [Accessed July 2013].

NSRDEC US Army Natick Soldier Research, Development and Engineering Center. Obtained through the Internet: http://nsrdec.natick.army.mil/ANSURII/index.htm [Accessed July 2013].

Reginster, JY. (2002) 'The prevalence and burden of arthritis', Rheumatology, Vol. 41 (Supp 1), pp. 3-6.

Siemens PLM software (2013) Tecnomatix JACK. Obtained through the Internet [Accessed July 2013]: http://www.plm.automation.siemens.com/en_us/products/tecnomatix/assembly_planning/jack/index.shtml

Sundin, A and Ortengren, R. (2006) 'Digital Human modelling for CAE applications', in Salvendy G (Ed.) Handbook of Human Factors and Ergonomics, 3rd Edition, John Wiley \& Sons, New York, NY, USA.

Tass International (2013) MADYMO Worldwide standard in occupant safety, Obtained through the Internet: http://www.tassinternational.com/madymo [Accessed July 2013]

Thalmann, D., Grillon, H., Maim, J. and Yersin, B. (2009), 'Challenges in Crowd Simulation', in Proceeding 2009 International Conference on Cyberworlds, Bradford, UK.

UNI-EN 1005-4:2005:E (2005). Safety of machinery - Human physical performance - Part 4: Evaluation of working postures and movements in relation to machinery. European Community for Standardization.

UNI-EN 1005-5:2007:E (2007). Safety of machinery - Human physical performance - Part 5: Risk assessment for repetitive handling at high frequency. European Community for Standardization.

van der Meulen, P., Seidl, A. (2007) 'Ramsis - the leading CAD tool for ergonomic analysis of vehicles', in Duffy VG (Ed.) Digital Human Modeling, HCI 2007, vol. LNCS 4561, Springer, Berlin Heidelberg.

Waters, R. T., Putz-Anderson, V., Garg, A., (1994) 'Application manual for the revised Niosh lifting equation' DHHS (NIOSH) Publication Number 94-110, US Department of Health and Human Services, Centre for Disease Control and Prevention, available at http://www.cdc.gov/niosh/docs/94-110/ (Accessed July 2013).

Zhang, L., Yuan, X., Wang, L., and Dong, D. (2007) 'Design and implementation of ergonomics evaluation system of 3D airplane cockpit' in Duffy VG (Ed.) Digital Human Modeling, HCI 2007, vol. LNCS 4561, Springer, Berlin Heidelberg. 